\title{
Hydrocarbon generation from lacustrine shales with retained oil during thermal maturation
}

\author{
Xin-He Shao ${ }^{1,2} \cdot$ Xiong-Qi Pang ${ }^{1,2} \cdot$ Mao-Wen $\mathrm{Li}^{3,4} \cdot$ Zhi-Ming Li $^{4} \cdot$ Yi Zhao ${ }^{1,2}$
}

Received: 7 January 2020 / Published online: 4 September 2020

(c) The Author(s) 2020

\begin{abstract}
Thermal maturation in the shale oil/gas system is inherently complex due to the competitive interplays between hydrocarbon generation and retention processes. To study hydrocarbon generation characteristics from shales within different stages of thermal maturation under the influence of retained oil, we performed Micro-Scale Sealed Vessels (MSSV) pyrolysis on a set of artificially matured lacustrine shale samples from the Shahejie Formation in the Dongpu Depression in Bohai Bay Basin, China. Experimental results show that hydrocarbon yields of shale samples with or without retained oil at various thermal maturities follow different evolution paths. Heavy components $\left(\mathrm{C}_{15+}\right)$ in samples crack at high temperatures and generally follow a sequence, where they first transform into $\mathrm{C}_{6-14}$ then to $\mathrm{C}_{2-5}$ and $\mathrm{C}_{1}$. Methane accounts for most of the gaseous products at high temperatures in all samples, with different origins. The cracking of $\mathrm{C}_{2-5}$ is the main methane-generating process in samples with retained oil, whereas the source of methane in samples without retained oil is kerogen. In the studied shales, retained oils at early-mature stage retard the transformation of liquid to gaseous hydrocarbon and prompt the cracking of $\mathrm{C}_{2-5}$ to $\mathrm{C}_{1}$ to some extent. TSR reaction related to gypsum in the studied samples is the primary reason that can explain the loss of hydrocarbon yields, especially at high temperatures. In addition, transformation of volatile hydrocarbons to gas and coke also accounts for the loss of generated hydrocarbon, as a secondary factor.
\end{abstract}

Keywords MSSV pyrolysis $\cdot$ Hydrocarbon generation $\cdot$ Lacustrine shales $\cdot$ Thermal maturation $\cdot$ Retained oil

\section{Introduction}

Hydrocarbon generation has been a topic of long-standing interest of petroleum geologists, and researchers have earned a lot of achievements in the last few decades (Tissot and

\section{Edited by Jie Hao}

Xiong-Qi Pang

pangxq@cup.edu.cn

1 State Key Laboratory of Petroleum Resources and Prospecting, China University of Petroleum, Beijing 102249, China

2 College of Geosciences, China University of Petroleum, Beijing 102249, China

3 State Key Laboratory of Shale Oil and Shale Gas Resources and Effective Development, SINOPEC Petroleum Exploration and Production Research Institute, Beijing 100083, China

4 SINOPEC Key Laboratory of Petroleum Accumulation Mechanisms, Wuxi Institute of Petroleum Geology, Wuxi 214126, Jiangsu, China
Welte 1978; Lewan and Roy 2011; Sondergeld et al. 2013). The general scheme proposed by Tissot and Welte (1978) describing hydrocarbon formation during burial of source rocks has been widely accepted, and numerous studies were carried out on this basis. In addition, techniques have been improved greatly these years to analyze hydrocarbon generation from source rocks. Rock-Eval pyrolysis, gold tube pyrolysis, Micro-Scale Sealed Vessels (MSSV) pyrolysis, semi-closed and closed-system hydrous pyrolysis are more and more common in laboratories (Lewan and Roy 2011; Behar et al. 1992; Horsfield et al. 1989; Peters et al. 2006; Wu et al. 2016). By heating organic matter at high temperatures for short times, these techniques can successfully simulate hydrocarbon generation processes that occur at lower temperature and rather long time in geological conditions (Spigolon et al. 2015). Thanks to the efforts that researchers have taken, we have a generally clear understanding on the properties of kerogens and hydrocarbon products at all stages of thermal maturation. Also, differences of hydrocarbon generation characteristics among kerogens from 
various sedimentary settings have been recognized (Braun et al. 1991; Burnham 1989).

Nowadays, as shale oil and gas, which are hydrocarbons retained in source rocks, are gaining increasingly important positions in fuel energy. The relationship between hydrocarbon generation, retention and expulsion has become an issue receiving much attention (Jia et al. 2014; Han et al. 2015; Ziegs et al. 2017). None of these three processes can be considered as independent, because they interact with each other during thermal maturation. Some studies report that hydrocarbon expulsion efficiency plays an important role on resource abundance in a shale oil/gas layer (Jarvie et al. 2007; Jia et al. 2014; Li et al. 2015). Petroleum geologists have found that retained oil in shales influences not only the gas generation potential at high maturities, but also the chemical compositions of gaseous products (Gai et al. 2015; Pan et al. 2012). In addition, researchers have stated that oil and gas released during hydrocarbon generation may attach to kerogens (Erdmann and Horsfield 2006; Mahlstedt et al. 2008; $\mathrm{Vu}$ et al. 2008). This recombination between hydrocarbon and kerogen structures at low thermal maturity can affect hydrocarbon generation at high maturity in different ways, depending on the types and thermal maturities of organic matters. Gai et al. (2015) used mixtures of immature kerogens and artificially matured oils in their pyrolysis experiments. The results suggested that interactions between kerogens and residual oils during hydrocarbon generation do not change total gas generation potential. Pan et al. (2012) conducted closed-system pyrolysis in gold tubes using mixed oil and pyrobitumen and suggested that existence of pyrobitumen can prompt methane generation by oil cracking. Compared to siliciclastic sandstones and carbonate rocks, shales have more diverse chemically unstable minerals, such as clay minerals, gypsum, halite. These inorganic minerals may also play a part in hydrocarbon generation by reacting with fluids or kerogens in shales. It is documented in some laboratory works that rock fabric can catalyze hydrocarbon generation (Rahman et al. 2018; Shao et al. 2018a, b). Overall, hydrocarbon generation in a shale play can be quite a complicated story. More works are needed on issues related to how exactly do organic and inorganic components in shales act during thermal maturation.

On the basis of previous studies, we tried to work out how retained oils with different thermal maturities affect the late hydrocarbon generation. By conducting MSSV pyrolysis experiments on shale samples with or without retained oil, the purpose of this research is attained from three aspects: (1) investigating hydrocarbon generation characteristics of a lacustrine shale throughout the thermal maturation process; (2) finding out the compositional differences between hydrocarbons generated from extracted and unextracted samples; and (3) studying how hydrocarbon yields from samples within different thermal maturity evolve when heating to different temperatures. In addition, to answer whether inorganic minerals affect hydrocarbon generation of lacustrine shales, we also use a kerogen sample for comparative study. Results from this study are expected to provide theoretical guidance in oil resource assessment of lacustrine shales.

\section{Samples and experiments}

\subsection{Sample preparation}

An immature shale core sample from the third member of Eocene Shahejie Formation $\left(\mathrm{Es}_{3}\right)$ in the Dongpu Depression in the Bohai Bay Basin, China, is used for sample preparation in this study. This sample has a burial depth of $1777 \mathrm{~m}$. The $\mathrm{Es}_{3}$ is considered as a major shale oil-gas exploration target in the Dongpu Depression. It is dominated by laminated organic-rich shales and gypsum-salt beds deposited in semi-deep and deep lacustrine settings (Shao et al. 2018a, b). The sample consists mainly of clay minerals $(42.0 \mathrm{wt} \%)$ and quartz (25.1 wt \%), as well as gypsum (15.0 wt \%), carbonate minerals (calcite: $4.7 \mathrm{wt} \%$; dolomite: $5.7 \mathrm{wt} \%)$, pyrite (6.5 $\mathrm{wt} \%)$ and halite $(1.1 \mathrm{wt} \%)$. The sample has a total organic carbon (TOC) content of $2.13 \mathrm{wt} \%$, a measured vitrinite reflectance $\left(R_{\mathrm{o}}\right)$ of $0.46 \%$ (Table 1$)$, and contains dominantly type I kerogens with minor type III kerogens. Geological settings and detailed sample information are documented in Shao et al. (2018a, b, 2020). In addition, bitumen is found in this sample, which could be mixture of migrated-in oil and early generated bitumen according to the saturates, aromatics, resins and asphaltenes (SARA) compositions (Table 1).

Fifty grams of the sample was treated with $\mathrm{HCl}$ and $\mathrm{HF}$ to obtain kerogen. Remnant shale sample was separated into three aliquots and crushed into fragments. Two aliquots of the shale fragments were heated in a semi-open hydrous pyrolysis system at $325{ }^{\circ} \mathrm{C}$ and $350{ }^{\circ} \mathrm{C}$ isothermally for $48 \mathrm{~h}$, respectively. By simulating hydrocarbon generation and expulsion from organic matters, semi-open hydrous pyrolysis can reflect complex thermal maturation process under geological conditions. To set boundary conditions in the semi-open hydrous pyrolysis, we referred to burial and thermal history of the area where the studied sample is from. Data were provided by Sinopec Zhongyuan Oilfield Company. In this way, oil-bearing samples with different thermal maturities, which can generally reflect hydrocarbon generation and expulsion in geological conditions, were obtained (Shao et al. 2020). Next, heated samples were crushed into powders (about 100 mesh), and each aliquot of samples was further divided into two aliquots, with one aliquot subjected to solvent extraction (dichloromethane, $72 \mathrm{~h}$ ) to remove the retained oil in samples. SARA compositions in extracts were separated using column chromatography. Heated extracted samples were also treated with $\mathrm{HCl}$ and $\mathrm{HF}$ to 
Table 1 Organic geochemical parameters of samples used in the MSSV pyrolysis experiment

\begin{tabular}{|c|c|c|c|c|c|c|c|}
\hline & Sample0-un & Sample0-ex & Sample325-un & Sample325-ex & Sample350-un & Sample350-ex & Sample-k \\
\hline TOC, wt $\%$ & 2.13 & 1.95 & 2.52 & 1.44 & 2.24 & 1.35 & 19.66 \\
\hline $\mathrm{S} 2, \mathrm{mg} / \mathrm{g}$ & 7.39 & 7.17 & 8.13 & 1.07 & 4.96 & 0.59 & 67.55 \\
\hline $\mathrm{S} 1, \mathrm{mg} / \mathrm{g}$ & 0.88 & - & 1.95 & - & 1.76 & - & \\
\hline Retained oil*, mg/g & 1.10 & - & 9.01 & - & 6.13 & - & - \\
\hline Saturate, $\%$ & 41.74 & - & 34.80 & - & 45.19 & - & - \\
\hline Aromatic, $\%$ & 9.61 & - & 14.42 & - & 13.78 & - & - \\
\hline Resin, \% & 39.04 & - & 27.27 & - & 25.64 & - & - \\
\hline Asphaltene, $\%$ & 9.61 & - & 23.51 & - & 15.38 & - & - \\
\hline$R_{\mathrm{o}}, \%$ & - & 0.46 & - & 1.37 & - & 1.62 & - \\
\hline
\end{tabular}

- no data

$*$ Retained oil $=\mathrm{S} 1_{\text {unextracted }}+\mathrm{S} 2_{\text {unextracted }}-\mathrm{S} 2_{\text {extracted }}($ Han et al. 2015)

obtain kerogen for $R_{\mathrm{o}}$ measurement. $R_{\mathrm{o}}$ values of sample and SARA compositions of retained oils can be found in Table 1.

\subsection{MSSV pyrolysis and products analysis}

MSSV pyrolysis was performed on the above-mentioned samples (two unheated whole-rock samples, four heated whole-rock samples and one kerogen sample). Apparatus and procedure of the MSSV pyrolysis are described in detail in the work of Horsfield and Dueppenbecker (1991). Here, 4-5 mg whole-rock samples or $<1 \mathrm{mg}$ kerogen samples were loaded into glass tubes. Clean silicon sands were added in tubes to fill in void volumes. The glass tubes were sealed with $\mathrm{H}_{2}$ flame and heated in a MSSV Sample Preparation Oven from room temperatures $\left(23^{\circ} \mathrm{C}\right)$ at a rate of $2{ }^{\circ} \mathrm{C} / \mathrm{min}$. The target heating temperatures for Sample-k, Sample0-un, Sample0-ex, Sample 325-un and Sample325-ex are 350, $375,400,425,450,475,500,525,550,575,600{ }^{\circ} \mathrm{C}$, while for Sample 350-un and Sample350-ex are 375, 400, 425, $450,475,500,525,550,575,600{ }^{\circ} \mathrm{C}$. Glass tubes were removed from the oven once they reached target temperatures and cooled down.

Generated hydrocarbon products from MSSV pyrolysis were quantitatively analyzed using an Agilent GC 7890B gas chromatograph (GC) apparatus equipped with a flame ionization detector (FID). Glass tubes were cracked open by a piston device in helium atmosphere at $300{ }^{\circ} \mathrm{C}$, and pyrolysis products are able to transferred into a liquid $\mathrm{N}_{2}$ cold trap for collection. These products were then released by heating the GC oven. The GC oven temperature was programmed to held at $40{ }^{\circ} \mathrm{C}$ for $13 \mathrm{~min}$ and then increases toward $320^{\circ} \mathrm{C}$ with a heating rate of $5^{\circ} \mathrm{C} / \mathrm{min}$, and isotherm time is $25 \mathrm{~min}$ for final temperature. At the first 9 min of the program, liquid $\mathrm{N}_{2}$ was used to keep trap temperature lower than boiling points of most hydrocarbons, while only methane could come out from the trap. Liquid $\mathrm{N}_{2}$ was removed afterward for the release of other hydrocarbon products. Hydrocarbon components are identified and quantified with GC ChemStation $($ software from Agilent Technologies.

\section{Results}

Yields of generated hydrocarbons during MSSV pyrolysis are summarized in Table 2, and details are described in the following sections.

\subsection{Pyrolysis products from the unheated samples}

The cumulative yields of total hydrocarbon products and different fractions including $\mathrm{C}_{1}, \mathrm{C}_{2-5}, \mathrm{C}_{6-14}$ and $\mathrm{C}_{15+}$ from Sample0-ex and Sample0-un are shown in Fig. 1. Total hydrocarbon yields of both samples reach their maximum at about $550{ }^{\circ} \mathrm{C}$ (temperature of maximal yields cannot be told exactly because there are $25{ }^{\circ} \mathrm{C}$ gaps between individual heating temperatures). The total yield from Sample0-un increases progressively to $177.85 \mathrm{mg} / \mathrm{g}$ TOC with temperature increasing toward $550{ }^{\circ} \mathrm{C}$. In comparison, the total yield from Sample0-ex displays a sharp increase from $33.09 \mathrm{mg} / \mathrm{g}$ TOC to $136.84 \mathrm{mg} / \mathrm{g}$ TOC in temperature range of $500{ }^{\circ} \mathrm{C}-550{ }^{\circ} \mathrm{C}$. $\mathrm{C}_{1}$ yield of Sample0-un reaches a maximum at $575{ }^{\circ} \mathrm{C}$ and then decreases slightly, while that of Sample0-ex maximizes at $550{ }^{\circ} \mathrm{C}$ and drops sharply at higher temperature. For Sample0-un, maximal yield of $\mathrm{C}_{6-14}$ appears at lower temperature than $\mathrm{C}_{2-5}$ components, while the evolution trends of $\mathrm{C}_{2-5}$ and $\mathrm{C}_{6-14}$ from Sample0-ex are similar. $\mathrm{C}_{15+}$ products of Sample0-un reach the maximal value at $425-450{ }^{\circ} \mathrm{C}$, while the evolution of $\mathrm{C}_{15+}$ yields from Sample0-ex shows a flat curve throughout the heating series.

Histograms showing percentages of hydrocarbon products from Sample0-un and Sample0-ex have generally similar appearance with $\mathrm{C}_{1}$ and $\mathrm{C}_{15+} \cdot \mathrm{C}_{1}$ increases and $\mathrm{C}_{15+}$ decreases with increasing temperature, which indicates that the hydrocarbon products tend to transform from high 
Table 2 Hydrocarbon yields of the unheated and artificially matured shale samples in the MSSV pyrolysis experiment

\begin{tabular}{|c|c|c|c|c|c|c|c|c|c|c|c|c|c|c|}
\hline \multirow[t]{2}{*}{$\begin{array}{l}\text { Tempera- } \\
\text { ture, }{ }^{\circ} \mathrm{C}\end{array}$} & \multicolumn{10}{|c|}{ Yield, mg/g TOC } & \multicolumn{4}{|c|}{$\begin{array}{l}\text { Calculated yield from per unit retained } \\
\text { oil, mg/g Oil* }\end{array}$} \\
\hline & Total & $\mathrm{C}_{1}$ & $\mathrm{C}_{2-5}$ & $\mathrm{C}_{6-14}$ & $\mathrm{C}_{15+}$ & Total & $\mathrm{C}_{1}$ & $\mathrm{C}_{2-5}$ & $\mathrm{C}_{6-14}$ & $\mathrm{C}_{15+}$ & $\overline{C_{1}}$ & $\mathrm{C}_{2-5}$ & $\mathrm{C}_{6-14}$ & $\mathrm{C}_{15+}$ \\
\hline & \multicolumn{5}{|c|}{ Sample0-un } & \multicolumn{5}{|c|}{ Sample0-ex } & & & & \\
\hline 350 & 8.42 & 0.07 & 1.05 & 0.25 & 7.05 & 4.92 & 0.97 & 0.33 & 0.43 & 3.18 & & & & \\
\hline 375 & 7.38 & 1.24 & 0.52 & 0.76 & 4.85 & 10.15 & 2.09 & 0.64 & 1.54 & 5.90 & & & & \\
\hline 400 & 17.78 & 2.63 & 0.50 & 1.58 & 13.06 & 7.11 & 0.61 & 0.52 & 1.54 & 4.44 & & & & \\
\hline 425 & 45.66 & 8.24 & 1.37 & 10.26 & 25.79 & 18.13 & 4.54 & 1.14 & 6.55 & 5.90 & & & & \\
\hline 450 & 63.65 & 18.27 & 4.69 & 17.06 & 23.63 & 20.94 & 8.59 & 0.83 & 7.32 & 4.21 & & & & \\
\hline 475 & 84.71 & 31.05 & 10.58 & 31.01 & 12.05 & 27.16 & 11.37 & 3.76 & 10.60 & 1.43 & & & & \\
\hline 500 & 142.20 & 86.40 & 15.26 & 35.09 & 5.44 & 33.09 & 23.80 & 0.97 & 7.96 & 0.35 & & & & \\
\hline 525 & 166.20 & 99.58 & 26.44 & 33.83 & 6.35 & 97.26 & 59.64 & 12.61 & 21.59 & 3.42 & & & & \\
\hline 550 & 177.85 & 117.00 & 23.18 & 27.70 & 9.96 & 136.84 & 88.56 & 17.03 & 28.97 & 2.27 & & & & \\
\hline 575 & 170.73 & 132.02 & 12.43 & 21.50 & 4.78 & 84.78 & 61.37 & 6.23 & 15.83 & 1.35 & & & & \\
\hline \multirow[t]{2}{*}{600} & 149.64 & 126.07 & 11.43 & 4.57 & 7.57 & 67.52 & 49.21 & 10.27 & 2.95 & 5.08 & & & & \\
\hline & \multicolumn{5}{|c|}{ Sample325-un } & \multicolumn{5}{|c|}{ Sample325-ex } & & & & \\
\hline 350 & 24.56 & 1.21 & 0.30 & 1.68 & 21.37 & 1.08 & 0.16 & 0.47 & 0.15 & 0.29 & 3.11 & 0.08 & 4.46 & 59.32 \\
\hline 375 & 23.11 & 0.59 & 0.16 & 1.00 & 21.35 & 1.98 & 0.82 & 0.27 & 0.52 & 0.37 & 0.36 & 0.03 & 1.95 & 59.13 \\
\hline 400 & 24.18 & 1.42 & 0.47 & 2.08 & 20.22 & 3.79 & 1.67 & 0.73 & 1.39 & 0.00 & 1.29 & 0.16 & 3.59 & 56.55 \\
\hline 425 & 31.52 & 4.83 & 1.00 & 5.32 & 20.38 & 3.50 & 1.79 & 0.46 & 0.99 & 0.27 & 10.65 & 2.06 & 13.29 & 56.56 \\
\hline 450 & 51.77 & 12.60 & 7.23 & 14.19 & 17.75 & 4.75 & 2.84 & 0.69 & 1.21 & 0.00 & 30.70 & 19.10 & 37.76 & 49.63 \\
\hline 475 & 83.98 & 44.46 & 4.62 & 28.04 & 6.86 & 9.35 & 6.78 & 0.95 & 1.62 & 0.00 & 113.50 & 11.41 & 75.82 & 19.20 \\
\hline 500 & 100.85 & 56.80 & 15.83 & 24.19 & 4.04 & 12.26 & 9.20 & 1.48 & 1.57 & 0.00 & 144.15 & 41.91 & 65.13 & 11.29 \\
\hline 525 & 104.48 & 75.74 & 6.52 & 20.60 & 1.63 & 21.04 & 16.94 & 1.93 & 2.17 & 0.00 & 184.75 & 15.15 & 54.14 & 4.55 \\
\hline 550 & 109.77 & 79.91 & 9.28 & 19.38 & 1.20 & 24.87 & 20.14 & 2.71 & 2.02 & 0.00 & 191.31 & 21.62 & 50.99 & 3.37 \\
\hline 575 & 76.65 & 62.62 & 3.14 & 10.09 & 0.80 & 12.17 & 10.71 & 1.08 & 0.38 & 0.00 & 158.02 & 7.06 & 27.61 & 2.25 \\
\hline \multirow[t]{2}{*}{600} & 58.50 & 48.56 & 3.85 & 5.72 & 0.37 & 12.81 & 11.07 & 1.42 & 0.32 & 0.00 & 118.13 & 8.49 & 15.48 & 1.05 \\
\hline & \multicolumn{5}{|c|}{ Sample350-un } & \multicolumn{5}{|c|}{ Sample350-ex } & & & & \\
\hline 375 & 24.13 & 0.39 & 0.24 & 0.55 & 22.96 & 6.13 & 0.73 & 0.51 & 0.42 & 4.48 & $-\underline{0.19}$ & $-\underline{0.26}$ & 1.08 & 74.05 \\
\hline 400 & 21.62 & 1.64 & 0.27 & 1.76 & 17.95 & 5.15 & 1.24 & 0.61 & 0.89 & 2.41 & 3.27 & $-\underline{0.36}$ & 4.47 & 60.27 \\
\hline 425 & 25.50 & 2.52 & 0.42 & 4.28 & 18.28 & 6.58 & 2.56 & 1.36 & 1.69 & 0.97 & 3.56 & $-\underline{1.44}$ & 11.90 & 64.67 \\
\hline 450 & 27.32 & 7.47 & 2.49 & 8.58 & 8.78 & 6.79 & 4.08 & 1.31 & 1.40 & 0.00 & 18.32 & 6.22 & 28.27 & 32.07 \\
\hline 475 & 32.70 & 17.00 & 2.99 & 11.01 & 1.70 & 13.59 & 9.14 & 1.87 & 2.58 & 0.00 & 41.98 & 6.79 & 34.57 & 6.23 \\
\hline 500 & 59.49 & 41.42 & 4.08 & 12.36 & 1.63 & 14.16 & 11.19 & 1.57 & 1.41 & 0.00 & 126.72 & 11.45 & 42.07 & 5.96 \\
\hline 525 & 63.07 & 47.13 & 5.11 & 10.46 & 0.37 & 19.08 & 14.73 & 1.61 & 1.72 & 1.01 & 139.79 & 15.13 & 34.42 & $-\underline{0.86}$ \\
\hline 550 & 66.27 & 51.92 & 4.69 & 9.17 & 0.49 & 33.46 & 27.11 & 3.59 & 2.56 & 0.21 & 130.01 & 9.25 & 27.88 & 1.32 \\
\hline 575 & 59.49 & 48.55 & 3.85 & 7.08 & 0.00 & 30.45 & 26.69 & 2.24 & 1.52 & 0.00 & 118.65 & 9.14 & 22.52 & 0.00 \\
\hline \multirow[t]{2}{*}{600} & 45.54 & 39.66 & 3.12 & 2.76 & 0.00 & 21.31 & 19.55 & 1.43 & 0.34 & 0.00 & 101.88 & 8.27 & 9.34 & 0.00 \\
\hline & \multicolumn{5}{|c|}{ Sample-k } & & & & & & & & & \\
\hline 350 & 17.92 & 1.73 & 0.17 & 0.68 & 15.35 & & & & & & & & & \\
\hline 375 & 34.94 & 3.65 & 0.33 & 2.12 & 28.83 & & & & & & & & & \\
\hline 400 & 57.05 & 6.84 & 1.72 & 6.73 & 41.76 & & & & & & & & & \\
\hline 425 & 76.23 & 13.22 & 5.27 & 16.67 & 41.07 & & & & & & & & & \\
\hline 450 & 105.96 & 29.69 & 5.15 & 24.63 & 46.49 & & & & & & & & & \\
\hline 475 & 112.08 & 36.64 & 19.27 & 38.68 & 17.49 & & & & & & & & & \\
\hline 500 & 138.70 & 49.28 & 42.23 & 39.26 & 7.92 & & & & & & & & & \\
\hline 525 & 173.63 & 84.71 & 36.08 & 40.99 & 11.85 & & & & & & & & & \\
\hline 550 & 170.53 & 99.69 & 22.18 & 38.02 & 10.64 & & & & & & & & & \\
\hline 575 & 168.45 & 107.43 & 19.09 & 33.18 & 8.75 & & & & & & & & & \\
\hline 600 & 156.58 & 110.03 & 10.14 & 26.30 & 10.11 & & & & & & & & & \\
\hline
\end{tabular}

Negative values marked with underlines may result from heterogeneity of the studied samples and small loading amounts of samples in each set of heating

$*$ Calculated yield from per unit retained oil $=1000 \times\left(\right.$ Yield $\left._{\mathrm{un}} \times \mathrm{TOC}_{\mathrm{un}}-\mathrm{Yield}_{\mathrm{ex}} \times \mathrm{TOC}_{\mathrm{ex}}\right) /$ Retained oil 

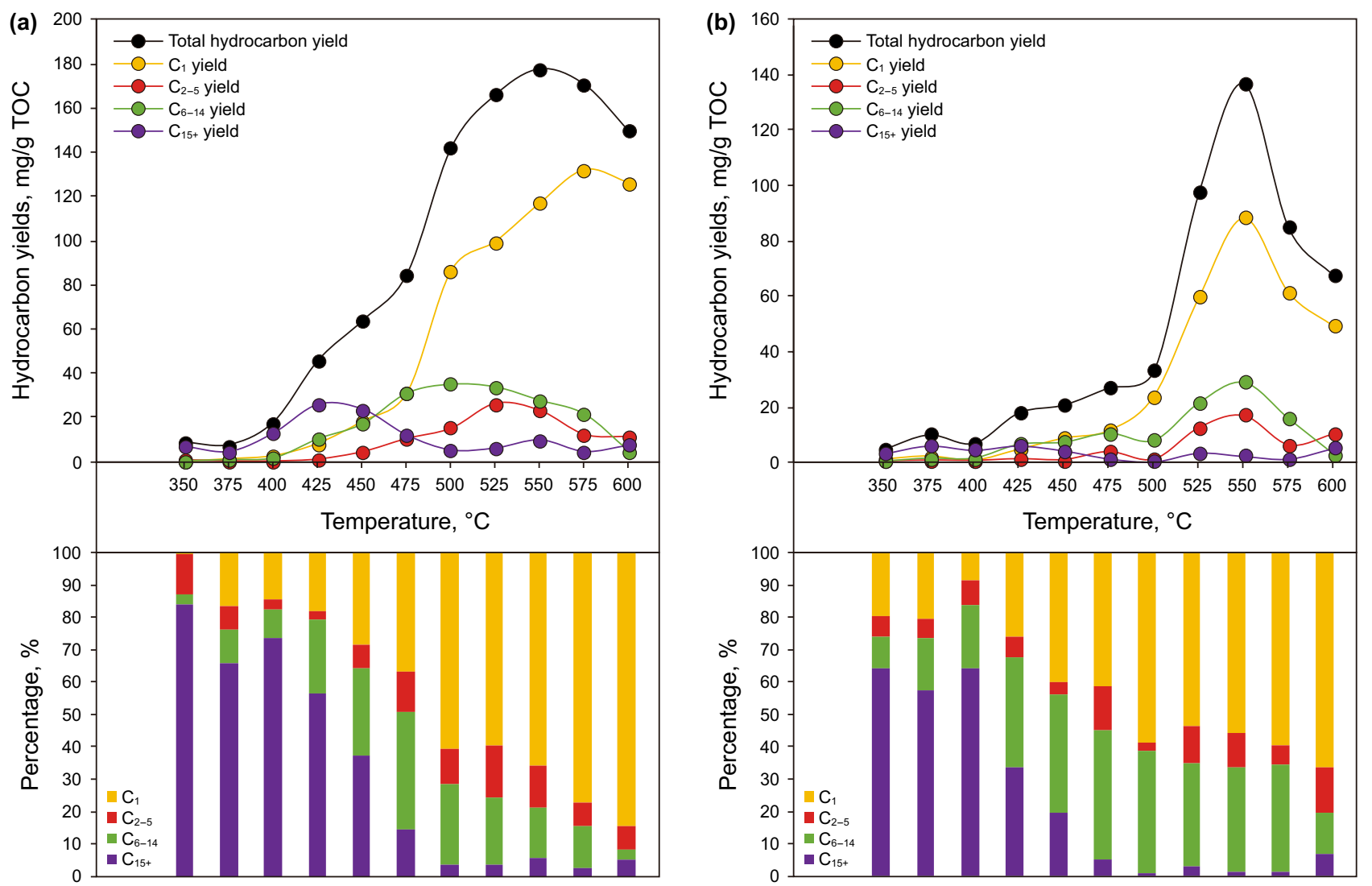

Fig. 1 Cumulative yields and percentages of $\mathrm{C}_{1}, \mathrm{C}_{2-5}, \mathrm{C}_{6-14}$ and $\mathrm{C}_{15+}$ from MSSV Pyrolysis of Sample0-un (a) and Sample0-ex (b)

molecular weight into low molecular weight components during thermal maturation. A difference in aspect of the evolution of $\mathrm{C}_{6-14}$ is worth noticing. At high-temperature range $\left(>500{ }^{\circ} \mathrm{C}\right.$ ), the percentage of $\mathrm{C}_{6-14}$ products from Sample0ex remains stable until about $575{ }^{\circ} \mathrm{C}$, compared to those from Sample0-un which decrease gradually.

\subsection{Pyrolysis products from the samples heated to $325^{\circ} \mathrm{C}$}

Sample325-un is the one that has the highest retained oil content $(9.01 \mathrm{mg} / \mathrm{g})$ among the studied samples, and the $R_{\mathrm{o}}$ datum indicates that this sample is at the transition from oil to gas window. Maximal total and $\mathrm{C}_{1}$ yields of Sample325-un and Sample325-ex all occur at around $550{ }^{\circ} \mathrm{C}$ (Fig. 2). For Sample325-un, yields of $\mathrm{C}_{6-14}$ maximize at about $475{ }^{\circ} \mathrm{C}$ and $\mathrm{C}_{2-5}$ yields reach the maximum at about $500{ }^{\circ} \mathrm{C}$. Differently, the highest contents of $\mathrm{C}_{2-5}$ and $\mathrm{C}_{6-14}$ components from Sample325-ex both appear at about $550{ }^{\circ} \mathrm{C}$, which are higher than those of Sample325un. $\mathrm{C}_{15+}$ components of Sample325-ex remain at low contents during the entire heating series $(<0.5 \mathrm{mg} / \mathrm{g}$ TOC), indicating a limited generation potential of large molecular weight hydrocarbons. In contrast, $\mathrm{C}_{15+}$ components take up most of hydrocarbon yields from Sample325-un at heating temperatures lower than $425^{\circ} \mathrm{C}$, which is from the retained oil in samples. Here, an abrupt decrease of $\mathrm{C}_{15+}$ yield from $450{ }^{\circ} \mathrm{C}$ to $475{ }^{\circ} \mathrm{C}$ is notable, companied by increasing of low molecular hydrocarbons such as $\mathrm{C}_{6-14}$ and $\mathrm{C}_{1}$.

Histograms of percentages of different hydrocarbon fractions from Sample325-un and Sample325-ex differ significantly from each other (Fig. 2). Light hydrocarbons $\left(\mathrm{C}_{1-5}\right)$ take predominance in total yields of Sample325un after the heating temperature is larger than $475{ }^{\circ} \mathrm{C}$, while they are dominant products in the entire heating series for Sample325-ex. The percentage of $\mathrm{C}_{6-14}$ from Sample325-un increases as heating temperature increases to $475^{\circ} \mathrm{C}$, and then decreases slightly or remain stable. In Sample325-ex, the percentage of $\mathrm{C}_{6-14}$ reaches a maximum at as early as $400{ }^{\circ} \mathrm{C}$ and then decreases gradually with increasing temperature. $\mathrm{C}_{15+}$ is the most important product of yield from Sample325-un at low temperatures and disappears at high heating temperatures. For Sample325-ex, the percentages of $\mathrm{C}_{15+}$ are low all the way. 

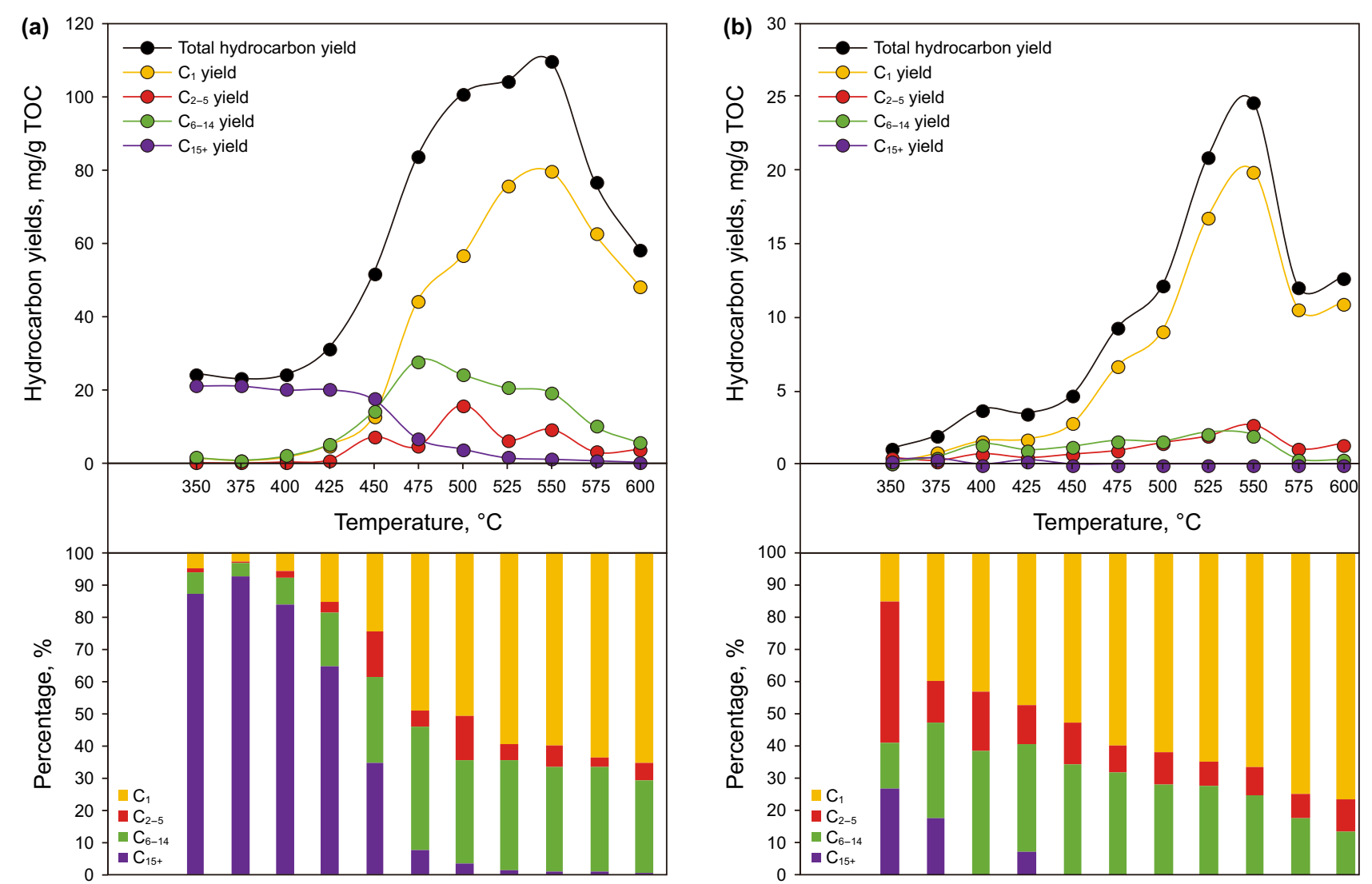

Fig. 2 Cumulative yields and percentages of $\mathrm{C}_{1}, \mathrm{C}_{2-5}, \mathrm{C}_{6-14}$ and $\mathrm{C}_{15+}$ from MSSV pyrolysis of Sample325-un (a) and Sample325-ex (b)

\subsection{Pyrolysis products from the samples heated to $350^{\circ} \mathrm{C}$}

Samples heated to $350{ }^{\circ} \mathrm{C}$ have the highest thermal maturity $\left(R_{\mathrm{o}}=1.62 \%\right)$ among the samples in this study and contain residual hydrocarbon with a content of $6.13 \mathrm{mg} / \mathrm{g}$. Similar to Sample325-un and Sample325-ex, the maximal values of total and $\mathrm{C}_{1}$ yields from Sample350-un and Sample350ex appear at around $550{ }^{\circ} \mathrm{C}$ (Fig. 3). $\mathrm{C}_{2-5}$ components of Sample350-un increase with increasing temperature toward $525^{\circ} \mathrm{C}$ and then remain stable until $600{ }^{\circ} \mathrm{C}$. $\mathrm{C}_{6-14}$ fractions from Sample350-un increase with increasing heating temperature till $500{ }^{\circ} \mathrm{C}$ and decrease gradually afterward. For Sample350-ex, $\mathrm{C}_{2-5}, \mathrm{C}_{6-14}$ and $\mathrm{C}_{15+}$ yield keep remaining in low contents ( $<5 \mathrm{mg} / \mathrm{g}$ TOC). $\mathrm{C}_{15+}$ yields from Sample350un are high at low heating temperature and decrease quickly from $4.48 \mathrm{mg} / \mathrm{g}$ TOC to $0 \mathrm{mg} / \mathrm{g}$ TOC during the heating range of $375^{\circ} \mathrm{C}-475{ }^{\circ} \mathrm{C}$, accompanied with increases of $\mathrm{C}_{1}$, $\mathrm{C}_{2-5}, \mathrm{C}_{6-14}$ yields.

According to the histograms showing percentages of yields of different fractions from Sample350-un and Sample350-ex, some differences can be found (Fig. 3). Percentages of $\mathrm{C}_{2-5}$ yields from Sample350-ex reach a maximum at about $425{ }^{\circ} \mathrm{C}$, while those from Sample350-un increase till $450{ }^{\circ} \mathrm{C}$ and then remain stable. The percentages of $\mathrm{C}_{6-14}$ from Sample350-un are overall higher than those from Sample350-ex and reach to a maximum at higher temperature at about $475^{\circ} \mathrm{C}$.

\subsection{Pyrolysis products from the kerogen}

Compositionally, properties of organic matters in Sample$\mathrm{k}$ are similar to those in Sample0-ex. The only difference between the two samples is that inorganic minerals in Sample-k have been washed out. Evolution of hydrocarbon generation from Sample-k is shown in Fig. 4. Total yield reaches a maximum at about $525^{\circ} \mathrm{C}$, which is earlier than Sample0-ex, and decreases slightly at higher heating temperatures. Unlike whole-rock samples whose $\mathrm{C}_{1}$ yields decrease at high temperatures, $\mathrm{C}_{1}$ yield of kerogen keeps increasing and reaches $110.03 \mathrm{mg} / \mathrm{g}$ TOC at $600{ }^{\circ} \mathrm{C}$. The maximum of $\mathrm{C}_{2-5}$ fraction occurs around $500^{\circ} \mathrm{C}$, and that of $\mathrm{C}_{6-14}$ fraction occurs at about $525{ }^{\circ} \mathrm{C}$. Hydrocarbon yields at low temperatures are dominated by $\mathrm{C}_{15+}$ fraction. $\mathrm{C}_{15+}$ yield increases with increasing temperature and reaches a plateau at about $400{ }^{\circ} \mathrm{C}$. It decreases significantly after temperature reaches 

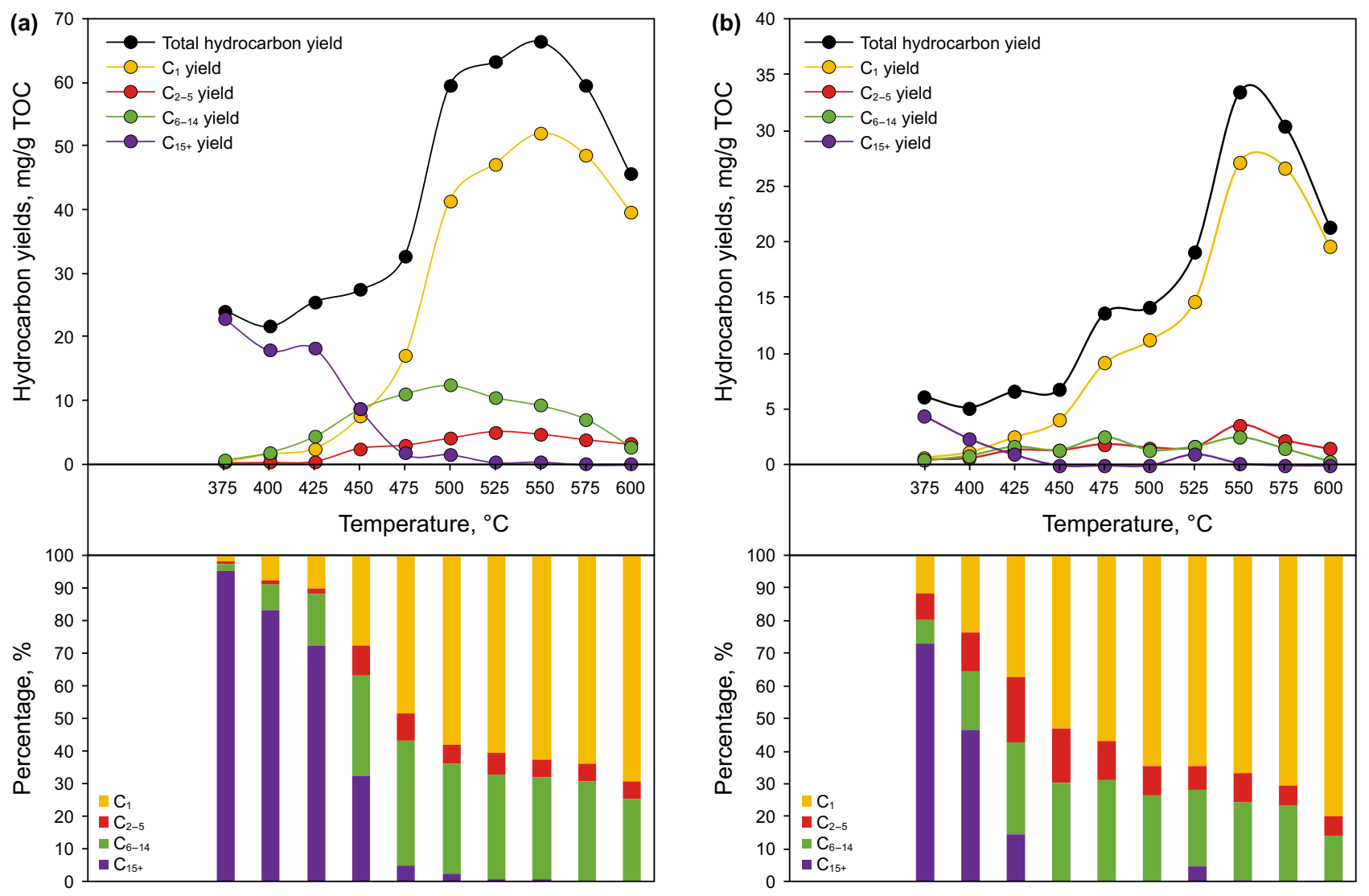

Fig. 3 Cumulative yields and percentages of $\mathrm{C}_{1}, \mathrm{C}_{2-5}, \mathrm{C}_{6-14}$ and $\mathrm{C}_{15+}$ from MSSV pyrolysis of Sample350-un (a) and Sample350-ex (b)

$450{ }^{\circ} \mathrm{C}$. At high-temperature range $\left(>500^{\circ} \mathrm{C}\right)$, light hydrocarbon fractions are dominant products.

According to the histogram showing the percentage of hydrocarbon yields from Sample-k, ratios of $\mathrm{C}_{1-5}, \mathrm{C}_{6-14}$ and $\mathrm{C}_{15+}$ remain unchanged when heating temperatures exceed $500{ }^{\circ} \mathrm{C}$ (Fig. 4). The percentages of $\mathrm{C}_{1-5}, \mathrm{C}_{6-14}$ and $\mathrm{C}_{15+}$ hydrocarbons at $600{ }^{\circ} \mathrm{C}$ are $76.75 \%, 16.79 \%$ and $6.45 \%$, respectively. Also, compared to Sample0-ex, percentages of heavy $\mathrm{C}_{15+}$ components from Sample-k are obviously higher at low-temperature ranges. The differences between whole-rock samples and kerogen on yields of hydrocarbon products during heating indicate that inorganic rock fabrics could have been involved in hydrocarbon generation during closed-system pyrolysis.

\section{Discussion}

\subsection{Hydrocarbon generation characteristics at different maturity}

Depolymerization reaction of kerogen and heavy hydrocarbons, $\mathrm{C}-\mathrm{C}$ bond cracking of $\mathrm{C}_{6+}$ saturated chains, demethylation reaction of aromatic structures and $\mathrm{C}-\mathrm{C}$ bond cracking of $\mathrm{C}_{3-5}$ aliphatic chains are four typical processes of thermal cracking of kerogens (Behar et al. 1992). The relative contributions from different hydrocarbon generation reactions through thermal maturation of shale remain a subject undergoing intense study (Tian et al. 2006; Vu et al. 2008; Guo et al. 2009).

MSSV yield of $\mathrm{C}_{15+}$ hydrocarbon from Sample325un reduces slowly at low temperatures, followed by rapid decrease with high temperatures, indicating that a thermal maturity threshold is required for the cracking of heavy components. To find out the differences between hydrocarbons generated from retained oils with different thermal maturities, hydrocarbon yields from retained oil were calculated and are listed in Table 2 and Fig. 5. Compared with Sanple350-un, retained oil in Sample325-un comprises higher contents of resin and asphaltene. $\mathrm{C}_{15+}$ yields from retained oil in Sample325-un and Sample350-un are similar. Yields of $\mathrm{C}_{1}, \mathrm{C}_{2-5}$ and $\mathrm{C}_{6-14}$ generated from retained oil in samples heated to $325{ }^{\circ} \mathrm{C}$ are larger than those from samples heated to $350{ }^{\circ} \mathrm{C}$. This is in agreement with previous studies reporting that resins and asphaltenes are main sources for saturates and aromatics (Ruble et al. 2001; Spigolon et al. 2015). The rapid increase of $\mathrm{C}_{6-14}$ fractions generated from retained oil begins at $400{ }^{\circ} \mathrm{C}$, while that of $\mathrm{C}_{1}$ occurs at $450{ }^{\circ} \mathrm{C}$. 


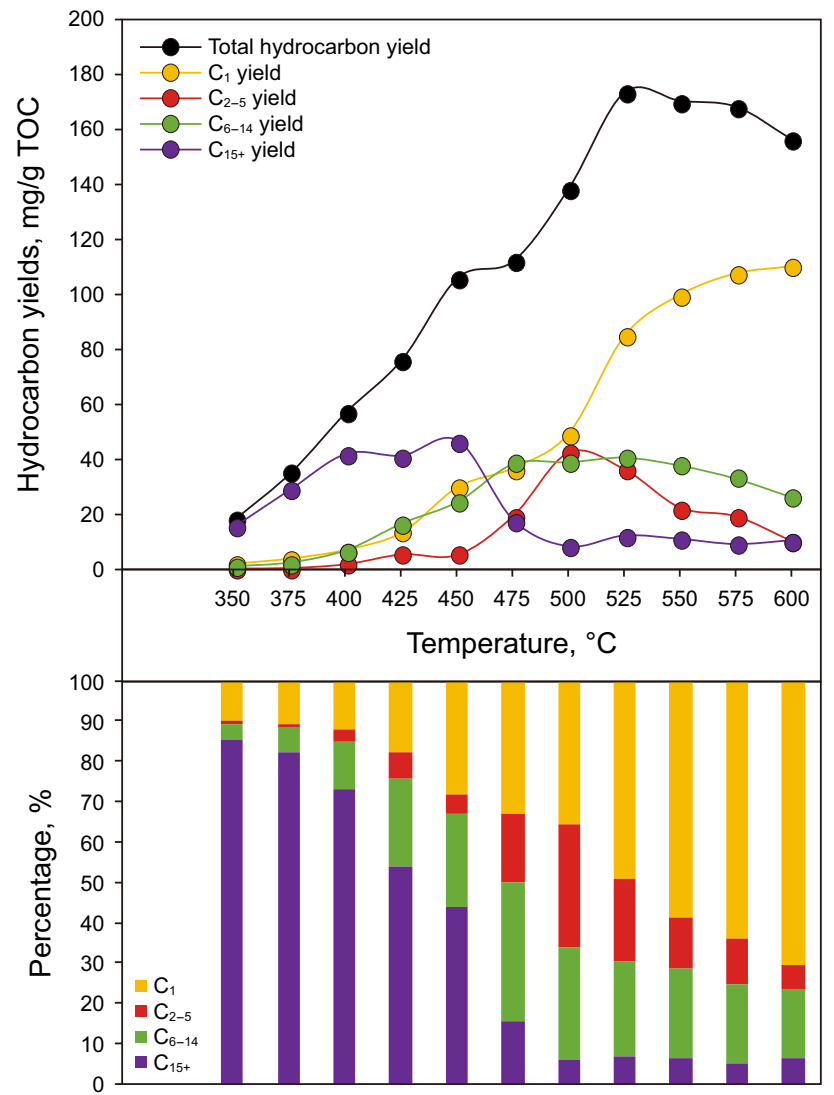

Fig. 4 Cumulative yields and percentages of $\mathrm{C}_{1}, \mathrm{C}_{2-5}, \mathrm{C}_{6-14}$ and $\mathrm{C}_{15+}$ from MSSV pyrolysis of Sample-k

Additionally, largest differences between $\mathrm{C}_{6-14}, \mathrm{C}_{2-5}, \mathrm{C}_{1}$ yields from retained oils in Sample325-un and Sample350un occur at $550{ }^{\circ} \mathrm{C}, 500{ }^{\circ} \mathrm{C}, 475^{\circ} \mathrm{C}$, respectively (dashed lines in Fig. 5). The above reflects that heavy hydrocarbons crack first into $\mathrm{C}_{6-14}$ and then gaseous light hydrocarbons during thermal maturation.

$\mathrm{C}_{15+}$ generation potentials of kerogens in Sample325 and Sample350 are almost depleted according to their measured Ro. Therefore, evolution trends of hydrocarbon yields from Sample325-un and Sample350-un can reflect the cracking of $\mathrm{C}_{15+}$ hydrocarbons that retained in shales. In general, the ends of rapid decreases of $\mathrm{C}_{15+}$ hydrocarbons correspond with the peaks of $\mathrm{C}_{6-14}$ yields in Sample325-un and Sample350-un, and the peaks of $\mathrm{C}_{2-5}$ yields typically occur at higher temperature than those of $\mathrm{C}_{6-14}$ hydrocarbons. Also, these $\mathrm{C}_{2-5}$ peaks in extracted samples appear at higher temperatures than in unextracted samples. Therefore, we could speculate a sequence of heavy hydrocarbon cracking in the studied $\mathrm{Es}_{3}$ shale and that light hydrocarbons at high-maturity stage are from different origins.

Methane is the main gaseous product for all samples in this study, especially at high thermal maturities. Whether methane is predominately generated by oil cracking or kerogen cracking has always been a hot research topic, and a lot of studies in laboratory and analyses on field gas samples has been performed (Behar et al. 1992, 2008; Guo et al. 2009; Prinzhofer and Huc 1995; Wang et al. 2013). According to the yield results of unextracted samples in our study, increases of $\mathrm{C}_{1}$ yields at high heating temperatures are accompanied by decreases of $\mathrm{C}_{2-5}$ yields. In contrast, this is not the same in extracted samples, where both $\mathrm{C}_{1}$ and $\mathrm{C}_{2-5}$ yields increase or $\mathrm{C}_{2-5}$ yields remain generally stable (Figs. 1, 2, 3). As suggested by previous studies, the process of oil cracking includes (1) long-chain aliphatic hydrocarbons into mainly $\mathrm{C}_{2-5}$ wet gas with a small amount of $\mathrm{C}_{1}$ at early stage and (2) $\mathrm{C}_{2-5}$ further cracking into $\mathrm{C}_{1}$ in late stage (Behar et al. 1992; Hill et al. 2003). Therefore, $C_{1}$ in extracted samples is mainly generated from primary kerogen cracking, and contribution from the $\mathrm{C}-\mathrm{C}$ bond cracking of $\mathrm{C}_{2-5}$ is limited. The rapid increases of $\mathrm{C}_{1}$ yields from unextracted samples at high-maturity range are from both the cracking of kerogen and $\mathrm{C}_{2-5}$, with the latter being the primary.

\subsection{Influences of retained oil at early-mature stage on hydrocarbon generation at high-maturity stage}

Original organic matters convert into different hydrocarbon fractions during thermal maturation, and kerogens and retained oil in shales act as intermediates in this process (Behar et al. 1992; Guo et al. 2009). Kerogens and oils formed at low-maturity stage can be regarded as sources of further hydrocarbon generation. Interaction between residual oil and kerogens at low-maturity stage is thought to have direct influences on potential and compositional properties of lately generated hydrocarbons (Erdmann and Horsfield 2006; McNeil and BeMent 1996; Dieckmann et al. 2006).

In this study, the ratios of light $\left(\mathrm{C}_{1-5}\right)$ to heavy $\left(\mathrm{C}_{6+}\right)$ hydrocarbons are applied to study the influences of retained oil in shales at low-maturity stage on hydrocarbon generation at high-maturity stage (Fig. 6). $\mathrm{C}_{1-5} / \mathrm{C}_{6+}$ ratios of all samples increase slowly below $550{ }^{\circ} \mathrm{C}$ and relatively fast at higher temperatures. This is because heavy hydrocarbons are primary products at relative low temperature, and gas is the major product at high temperature. The $\mathrm{C}_{1-5} / \mathrm{C}_{6+}$ ratios of Sample325-ex and Sample350-ex climb to rather high values rapidly after temperature reach above $550{ }^{\circ} \mathrm{C}$, suggesting that these two samples are more prone to yield gas. The two samples have rather low $\mathrm{C}_{6+}$ yields during heating, and thus $\mathrm{C}_{1-5}$ yields can be roughly considered as derived from kerogens. In the classical hydrocarbon generation model proposed by Tissot and Welte (1978), all liquid hydrocarbons are destined to crack into gas at a given temperature. Therefore, it is reasonable to inferred that residual oil at 

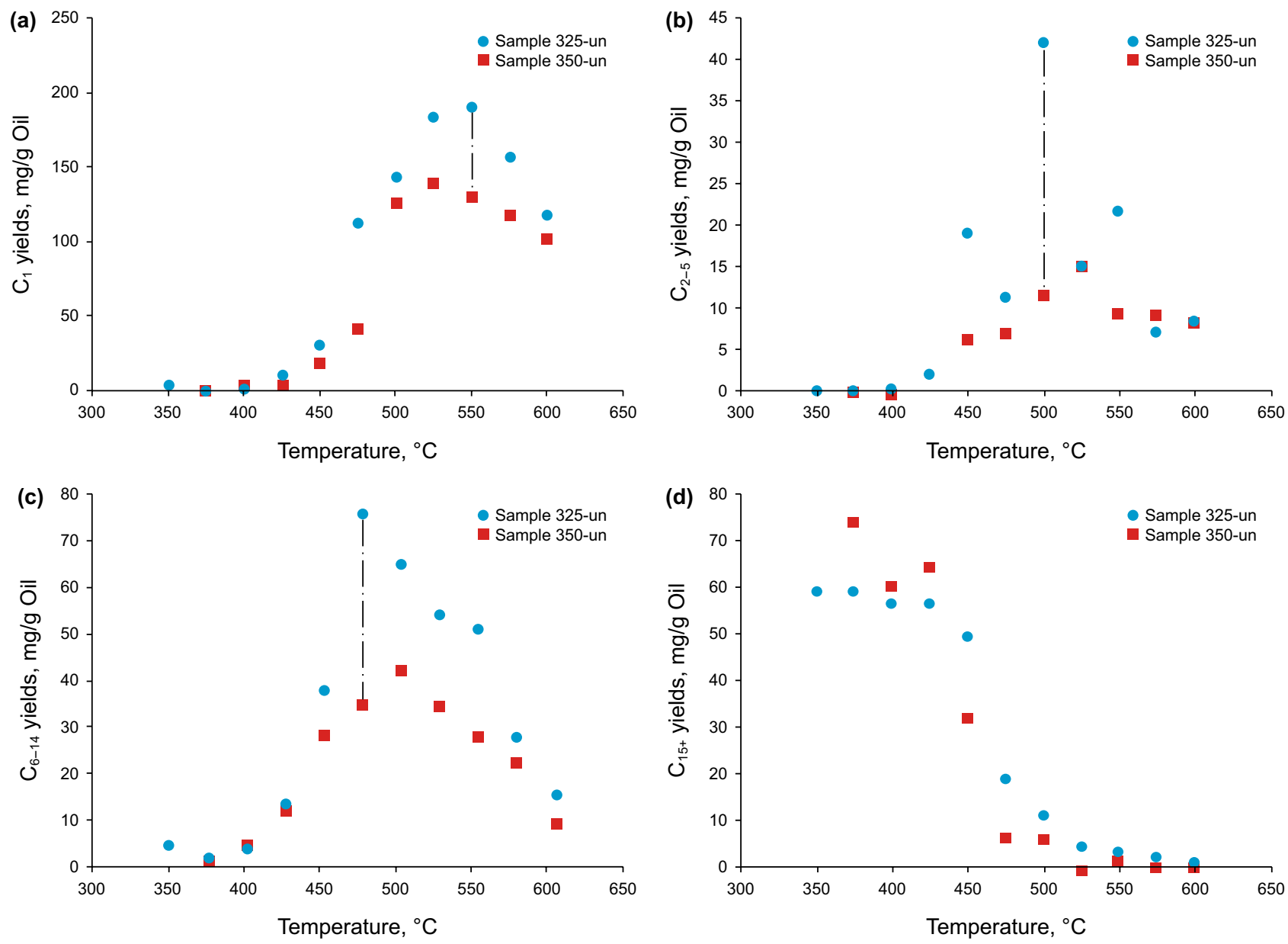

Fig. 5 Hydrocarbon yields from retained oils in Sample325-un and Sample350-un: a $\mathrm{C}_{1}$ yield; $\mathbf{b} \mathrm{C}_{2-5}$ yield; $\mathbf{c} \mathrm{C}_{6-14}$ yield; $\mathbf{d} \mathrm{C}_{15+}$ yield
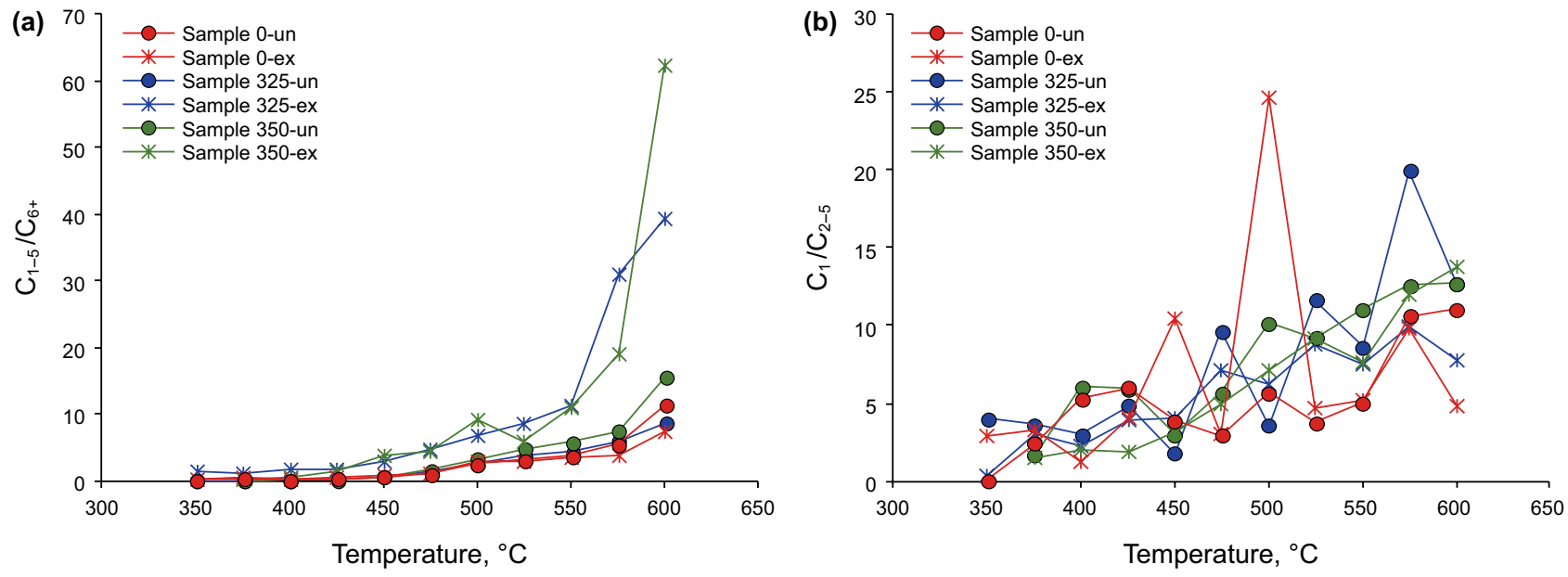

Fig. 6 Evolution of $\mathrm{C}_{1-5} / \mathrm{C}_{6+}(\mathbf{a})$ and $\mathrm{C}_{1} / \mathrm{C}_{2-5}(\mathbf{b})$ ratios in MSSV pyrolysis

early-mature stage may delay or extend the process of gas release at high-maturity stage in shales.
To figure out whether early retained oil in shales influences cracking of $\mathrm{C}_{2-5}$, the changes of $\mathrm{C}_{1} / \mathrm{C}_{2-5}$ during thermal maturation were studied. $\mathrm{C}_{1} / \mathrm{C}_{2-5}$-values of the 
whole-rock samples increase from low to high heating temperatures with fluctuations (Fig. 6b), which can be attributable to the contributions from both the generation of $\mathrm{C}_{2-5}$ and transformation from $\mathrm{C}_{2-5}$ to $\mathrm{C}_{1}$. Sample325-un, which contain the highest content of residual oil, has larger $\mathrm{C}_{1} /$ $\mathrm{C}_{2-5}$ values than Sample325-ex when heating temperatures exceed $525{ }^{\circ} \mathrm{C}$. Gas products from Sample350-un are slightly dryer than those from Sample350-ex, when heating temperature exceeds $475^{\circ} \mathrm{C}$. This reflected that residual oil may prompt the cracking of $\mathrm{C}_{2-5}$ to $\mathrm{C}_{1}$, while the effect is not quite distinct. As mentioned in previous studies, the absorption of retained oil into kerogen structures dominated by aromatic rings at low-maturity stage affects the release of methane at high-maturity stage (Gai et al. 2015; Pan et al. 2012; McNeil and BeMent 1996). The unheated sample in this study contains type I kerogens and minor type III kerogens and is thus dominated by aliphatic chains with minor aromatic groups. Kerogens in artificially matured Sample 325 and Sample 350 contain more aromatic clusters, due to higher thermal maturity. Therefore, changes of kerogen structures during thermal maturation affect the interaction between hydrocarbon products and kerogens and further influence late gas generation.

Hydrocarbon products generated during thermal maturation become progressively enriched in light component with heavy components disappearing gradually. In this process, the residual oil in shales may affect late hydrocarbon generation by buffering liquid hydrocarbons to gas and accelerating the cracking of $\mathrm{C}_{2-5}$ to methane moderately.

\subsection{Loss of hydrocarbon yields during thermal maturation}

A phenomenon worth noticing in our experimental work is that total and $\mathrm{C}_{1}$ yields show significant decreases at high heating temperatures, which is different from previous work from other researchers (Horsfield and Dueppenbecker 1991; Behar et al. 1992; Li et al. 2018). There are two potential reasons for this: (1) transformation from volatile hydrocarbons to gas and coke; (2) reaction between inorganic materials in rocks and hydrocarbons.

It is widely accepted that hydrocarbons transform to dry gas and coke at postmature stage of thermal evolution of source rock (Tissot and Welte 1978; Horsfield et al. 1992). This is a possible explanation for the reducing yields of $\mathrm{C}_{2+}$ hydrocarbons. With regard to methane, which is relatively stable and decomposes only at extremely high temperature over $1000{ }^{\circ} \mathrm{C}$ without oxygen, more reasonable explanation needs to be given. Inasmuch as neither did we have temperature above $1000{ }^{\circ} \mathrm{C}$, nor complete isolation from oxygen in the experiment.

As a self-generation and self-accumulation system, a variety of reactions between fluid and rock fabrics take place in shale reservoir during thermal maturation. Mineral composition as well as rock texture is involved in the processes of hydrocarbon generation and retention in shales, physically and chemically (Rahman et al. 2018; Shao et al. 2018a, b; Lewan et al. 2014). Thermochemical sulfate reduction (TSR) is a thermally driven reaction between hydrocarbons and sulfates and has been reported to be responsible for high $\mathrm{H}_{2} \mathrm{~S}$ concentrations in many petroleum accumulations (Krouse et al. 1988; Orr 1974; Worden et al. 1995; Cross et al. 2004). Theoretically, the reaction can occur at temperatures exceeding $25^{\circ} \mathrm{C}$ (Amurskii et al. 1977; Worden and Smalley 1996; Schenk and Horsfield 1993). In geological conditions, the initiation of the reaction at much higher temperatures is reported, according to studies on petroleum reservoirs having experienced TSR (Krouse et al. 1988; Worden et al. 1995; Machel et al. 1995):

$\mathrm{SO}_{4}^{2-}+\mathrm{CH}_{4} \rightarrow \mathrm{CO}_{2}+\mathrm{H}_{2} \mathrm{~S}+2 \mathrm{OH}^{-}$(methane as an example)

The selected sample in this study contains $15 \mathrm{wt} \%$ gypsum, which is unstable under high temperature and can be a potential source of sulfur. Therefore, it is plausible to consider that TSR was involved in the experiment and resulted in the decrease of cumulative hydrocarbon yields. To testify the speculation, a comparison is made between Sample-k and Sample0-ex. One of the salient differences between two samples is the evolution of methane yield at high temperature: methane yield from Sample-k increases till $600{ }^{\circ} \mathrm{C}$ and tends to be stable, while that from Sample0ex shows a rapid decrease after reaching its maximum at $525^{\circ} \mathrm{C}$. By looking over the total yields from two samples, we can find that hydrocarbon yields from Sample-k are much larger than those from whole-rock samples. This is a strong evidence suggesting that hydrocarbon was consumed by mineral components in shales during thermal maturation. Figure 7 shows the percentage decreases of $C_{1}$ and total yields of the studied samples according to the ratio of final yield to maximum yield. It is interesting that the decreases of $\mathrm{C}_{1}$ and total yields from Sample350 series are smaller than those from Sample0-ex and Sample325 series. This could be attributed to loss of gypsum during sample preparation by heating samples in semi-open hydrous pyrolysis system. In addition, percentage decreases of hydrocarbon yield in extracted samples are higher than those in unextracted samples, and loss of hydrocarbon yields in Sample0-un is minimal (Fig. 7). Hence, it can be inferred that TSR occurred during our experiments (there may not be enough gypsum for the consumption of larger amount of hydrocarbon products from unextracted samples). Whether this TSR reaction occurs in shale oil/gas layers under geological conditions remains to be examined and further works on natural shale samples are necessary. If TSR has an influence on hydrocarbon generation in shale layers when the burial depth is 

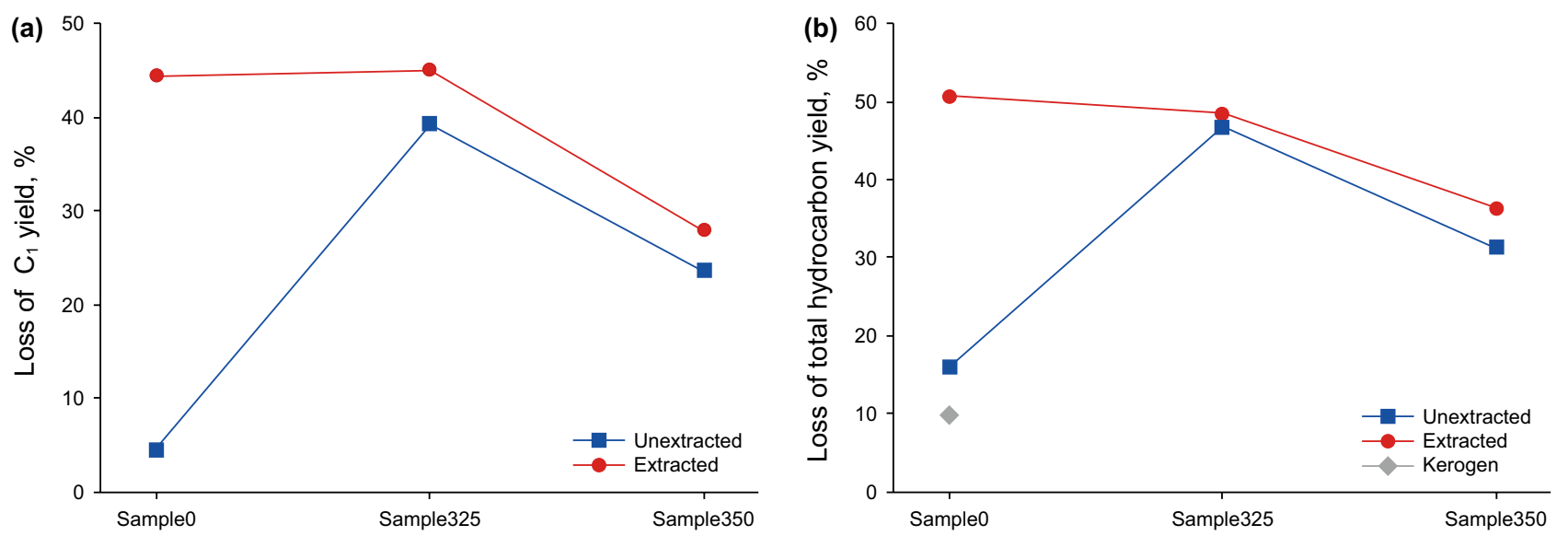

Fig. 7 Percentage decreases at high heating temperatures of $\mathrm{C}_{1}(\mathbf{a})$ and total hydrocarbon (b) yields of the studied samples

large enough, a practical implication from the above is that great caution should be taken when evaluating hydrocarbon resources from deep-buried gypsum-bearing shale system.

\section{Conclusions}

By conducting MSSV pyrolysis experiments on artificially matured lacustrine shale samples, we studied hydrocarbon generation characteristics of shales with the influence of retained oil. Hydrocarbon yields from samples with or without retained oil at different thermal maturities follow different evolution paths. Total yields of all whole-rock samples reach their maximum at heating temperature of about $550{ }^{\circ} \mathrm{C}$, followed by significant decreases. Maximal total yield of kerogen sample occurs around $525{ }^{\circ} \mathrm{C}$ and decreases slightly afterward. Besides, evolutions of $\mathrm{C}_{2-5}$, $\mathrm{C}_{6-14}$ and $\mathrm{C}_{15+}$ yields vary from sample to sample. The cracking of $\mathrm{C}_{15+}$ in the studied lacustrine shales generally follows a sequence as they first transform into $\mathrm{C}_{6-14}$ liquid hydrocarbons and then further crack into $\mathrm{C}_{2-5}$ gaseous hydrocarbons. Methane is the major gas product in all samples, and there are different origins. Cracking of $\mathrm{C}_{2+}$ is the major origin for methane generation in shales with retained oil, while methane in extracted shale samples is largely contributed from primary kerogen cracking. In the studied lacustrine shale samples, the process of oil transforming to gas is extended by oil retained at lowmaturity stage. In addition, retained oil may also slightly prompt the cracking of $\mathrm{C}_{2-5}$ to methane. Gypsum in samples is responsible for most of the hydrocarbon loss during heating, especially at high temperatures. Conversion of volatile hydrocarbons to gas and coke can be a secondary factor resulting in the decrease of $\mathrm{C}_{2+}$ yield at high heating temperatures.
Acknowledgements This research was funded by National Natural Science Foundation of China (No. 41872148) and China Major Research and Development Program for Oil and Gas (No. 2017ZX05049001). Xinhe Shao acknowledges the financial supporting from China Scholarship Council and American Association of Petroleum Geologists (Norman H. Foster Memorial Grant). We thank Sinopec Zhongyuan Oilfield Company for providing samples and background geological data in this study.

Open Access This article is licensed under a Creative Commons Attribution 4.0 International License, which permits use, sharing, adaptation, distribution and reproduction in any medium or format, as long as you give appropriate credit to the original author(s) and the source, provide a link to the Creative Commons licence, and indicate if changes were made. The images or other third party material in this article are included in the article's Creative Commons licence, unless indicated otherwise in a credit line to the material. If material is not included in the article's Creative Commons licence and your intended use is not permitted by statutory regulation or exceeds the permitted use, you will need to obtain permission directly from the copyright holder. To view a copy of this licence, visit http://creativecommons.org/licenses/by/4.0/.

\section{References}

Amurskii GI, Goncharov ES, Zhabrev IP, et al. Genesis of $\mathrm{H}_{2} \mathrm{~S}$-containing natural gases of oil and gas basins. Soviet Geol. 1977;5:56-68.

Behar F, Kressmann S, Rudkiewicz JL, et al. Experimental simulation in a confined system and kinetic modelling of kerogen and oil cracking. Org Geochem. 1992;19(1-3):173-89. https://doi. org/10.1016/0146-6380(92)90035-V.

Behar F, Lorant F, Lewan M. Role of NSO compounds during primary cracking of a Type II kerogen and a Type III lignite. Org Geochem. 2008;39(1):1-22. https://doi.org/10.1016/j.orggeochem .2007.10.007.

Braun RL, Burnham AK, Reynolds JG, et al. Pyrolysis kinetics for lacustrine and marine source rocks by programmed micropyrolysis. Energy Fuels. 1991;5(1):192-204. https://doi.org/10.1021/ ef00025a033. 
Burnham AK. A simple kinetic model of petroleum formation and cracking (No. UCID-21665). Lawrence Livermore National Lab., CA (USA). 1989.

Cross MM, Manning DA, Bottrell SH, et al. Thermochemical sulphate reduction (TSR): experimental determination of reaction kinetics and implications of the observed reaction rates for petroleum reservoirs. Org Geochem. 2004;35(4):393-404. https://doi. org/10.1016/j.orggeochem.2004.01.005.

Dieckmann V, Ondrak R, Cramer B, et al. Deep basin gas: new insights from kinetic modelling and isotopic fractionation in deep-formed gas precursors. Mar Pet Geol. 2006;23(2):183-99. https://doi. org/10.1016/j.marpetgeo.2005.08.002.

Erdmann M, Horsfield B. Enhanced late gas generation potential of petroleum source rocks via recombination reactions: evidence from the Norwegian North Sea. Geochim Cosmochim Acta. 2006;70(15):3943-56. https://doi.org/10.1016/j.gca.2006.04.003.

Gai H, Xiao X, Cheng P, et al. Gas generation of shale organic matter with different contents of residual oil based on a pyrolysis experiment. Org Geochem. 2015;78:69-78. https://doi.org/10.1016/j. orggeochem.2014.11.001

Guo L, Xiao X, Tian H, et al. Distinguishing gases derived from oil cracking and kerogen maturation: insights from laboratory pyrolysis experiments. Org Geochem. 2009;40(10):1074-84. https://doi. org/10.1016/j.orggeochem.2009.07.007.

Han Y, Mahlstedt N, Horsfield B. The Barnett Shale: compositional fractionation associated with intraformational petroleum migration, retention, and expulsion. AAPG Bull. 2015;99(12):2173202. https://doi.org/10.1306/06231514113.

Hill RJ, Tang Y, Kaplan IR. Insights into oil cracking based on laboratory experiments. Org Geochem. 2003;34(12):1651-72. https:// doi.org/10.1016/S0146-6380(03)00173-6.

Horsfield B, Dueppenbecker SJ. The decomposition of Posidonia Shale and Green River Shale kerogens using microscale sealed vessel (MSSV) pyrolysis. J Anal Appl Pyrol. 1991;20:107-23. https:// doi.org/10.1016/0165-2370(91)80066-H

Horsfield B, Disko U, Leistner F. The micro-scale simulation of maturation: outline of a new technique and its potential applications. Geol Rundsch. 1989;78(1):361-73.

Horsfield B, Schenk HJ, Mills N, et al. An investigation of the inreservoir conversion of oil to gas: compositional and kinetic findings from closed-system programmed-temperature pyrolysis. Org Geochem. 1992;19(1-3):191-204. https://doi.org/10.1016/01466380(92)90036-W.

Jarvie DM, Hill RJ, Ruble TE, et al. Unconventional shale-gas systems: the Mississippian Barnett Shale of north-central Texas as one model for thermogenic shale-gas assessment. AAPG Bull. 2007;91(4):475-99. https://doi.org/10.1306/12190606068.

Jia W, Wang Q, Liu J, et al. The effect of oil expulsion or retention on further thermal degradation of kerogen at the high maturity stage: a pyrolysis study of type II kerogen from Pingliang shale, China. Org Geochem. 2014;71:17-29. https://doi.org/10.1016/j. orggeochem.2014.03.009.

Krouse HR, Viau CA, Eliuk LS, et al. Chemical and isotopic evidence of thermochemical sulphate reduction by light hydrocarbon gases in deep carbonate reservoirs. Nature. 1988;333(6172):415-9.

Lewan MD, Roy S. Role of water in hydrocarbon generation from Type-I kerogen in Mahogany oil shale of the Green River Formation. Org Geochem. 2011;42(1):31-41. https://doi.org/10.1016/j. orggeochem.2010.10.004.

Lewan MD, Dolan MP, Curtis JB. Effects of smectite on the oil-expulsion efficiency of the Kreyenhagen Shale, San Joaquin Basin, California, based on hydrous-pyrolysis experiments. AAPG Bull. 2014;98(6):1091-109. https://doi.org/10.1306/10091313059.

Li J, Wang W, Cao Q, et al. Impact of hydrocarbon expulsion efficiency of continental shale upon shale oil accumulations in eastern
China. Mar Pet Geol. 2015;59:467-79. https://doi.org/10.1016/j. marpetgeo.2014.10.002.

Li X, Krooss BM, Ostertag-Henning C, et al. Liberation of hydrogencontaining gases during closed system pyrolysis of immature organic matter-rich shales. Int J Coal Geol. 2018;85:23-32. https ://doi.org/10.1016/j.coal.2017.11.001.

Machel HG, Krouse HR, Sassen R. Products and distinguishing criteria of bacterial and thermochemical sulfate reduction. Appl Geochem. 1995;10(4):373-89. https://doi.org/10.1016/08832927(95)00008-8.

Mahlstedt N, Horsfield B, Dieckmann V. Second order reactions as a prelude to gas generation at high maturity. Org Geochem. 2008;39(8):1125-9. https://doi.org/10.1016/j.orggeochem .2008.04.011.

McNeil RI, BeMent WO. Thermal stability of hydrocarbons: laboratory criteria and field examples. Energy Fuels. 1996;10(1):60-7. https ://doi.org/10.1021/ef9501399.

Orr WL. Changes in sulfur content and isotopic ratios of sulfur during petroleum maturation-study of Big Horn Basin Paleozoic oils. AAPG Bull. 1974;58(11):2295-318. https://doi. org/10.1306/83D91B9B-16C7-11D7-8645000102C1865D.

Pan C, Jiang L, Liu J, et al. The effects of pyrobitumen on oil cracking in confined pyrolysis experiments. Org Geochem. 2012;45:29-47. https://doi.org/10.1016/j.orggeochem.2012.01.008.

Peters KE, Walters CC, Mankiewicz PJ. Evaluation of kinetic uncertainty in numerical models of petroleum generation. AAPG Bull. 2006;90(3):387-403. https://doi.org/10.1306/10140505122.

Prinzhofer AA, Huc AY. Genetic and post-genetic molecular and isotopic fractionations in natural gases. Chem Geol. 1995;126(34):281-90. https://doi.org/10.1016/0009-2541(95)00123-9.

Rahman HM, Kennedy M, Löhr S, et al. The influence of shale depositional fabric on the kinetics of hydrocarbon generation through control of mineral surface contact area on clay catalysis. Geochim Cosmochim Acta. 2018;220:429-48. https://doi.org/10.1016/j. gca.2017.10.012.

Ruble TE, Lewan MD, Philp RP. New insights on the Green River petroleum system in the Uinta basin from hydrous pyrolysis experiments. AAPG Bull. 2001;85(8):1333-71. https://doi. org/10.1306/8626CAB9-173B-11D7-8645000102C1865D.

Schenk HJ, Horsfield B. Kinetics of petroleum generation by programmed-temperature closed-versus open-system pyrolysis. Geochim Cosmochim Acta. 1993;57(3):623-30. https://doi. org/10.1016/0016-7037(93)90373-5.

Shao D, Ellis GS, Li Y, et al. Experimental investigation of the role of rock fabric in gas generation and expulsion during thermal maturation: anhydrous closed-system pyrolysis of a bitumen-rich Eagle Ford Shale. Org Geochem. 2018a;119:22-35. https://doi. org/10.1016/j.orggeochem.2018.01.012.

Shao X, Pang X, Li H, et al. Pore network characteristics of lacustrine shales in the Dongpu Depression, Bohai Bay Basin, China, with implications for oil retention. Mar Pet Geol. 2018b;96:457-73. https://doi.org/10.1016/j.marpetgeo.2018.06.015.

Shao X, Pang X, Li M, et al. Hydrocarbon retention in lacustrine shales during thermal maturation: insights from semi-open system pyrolysis. J Pet Sci Eng. 2020;184:106480. https://doi.org/10.1016/j. petrol.2019.106480.

Sondergeld CH, Rai CS, Curtis ME. Relationship between organic shale microstructure and hydrocarbon generation. In: SPE unconventional resources conference-USA. Society of Petroleum Engineers. 2013, April. https://doi.org/10.2118/164540-MS.

Spigolon AL, Lewan MD, de Barros Penteado HL, et al. Evaluation of the petroleum composition and quality with increasing thermal maturity as simulated by hydrous pyrolysis: a case study using a Brazilian source rock with Type I kerogen. Org Geochem. 2015;83:27-53. https://doi.org/10.1016/j.orggeochem .2015.03.001. 
Tian H, Wang Z, Xiao Z, et al. Oil cracking to gases: kinetic modeling and geological significance. Chin Sci Bull. 2006;51(22):2763-70. https://doi.org/10.1007/s11434-006-2188-8.

Tissot BP, Welte DH. Petroleum formation and occurrence: a new approach to oil and gas exploration. Berlin: Springer; 1978. p. 538.

Vu TA, Horsfield B, Sykes R. Influence of in situ bitumen on the generation of gas and oil in New Zealand coals. Org Geochem. 2008;39(11):1606-19. https://doi.org/10.1016/j.orggeochem 2008.07.005.

Wang Q, Lu H, Greenwood P, et al. Gas evolution during kerogen pyrolysis of Estonian Kukersite shale in confined gold tube system. Org Geochem. 2013;65:74-82. https://doi.org/10.1016/j. orggeochem.2013.10.006.
Worden H, Smalley PC. $\mathrm{H}_{2} \mathrm{~S}$-producing reactions in deep carbonate gas reservoirs: Khuff Formation, Abu Dhabi. Chem Geol. 1996;133(1-4):157-71. https://doi.org/10.1016/S0009 -2541(96)00074-5.

Worden H, Smalley C, Oxtoby NH. Gas souring by thermochemical sulfate reduction at 140. AAPG Bull. 1995;79(6):854-63.

$\mathrm{Wu}$ Y, Ji L, He C, et al. The effects of pressure and hydrocarbon expulsion on hydrocarbon generation during hydrous pyrolysis of type-I kerogen in source rock. J Nat Gas Sci Eng. 2016;34:1215-24. https://doi.org/10.1016/j.jngse.2016.08.017.

Ziegs V, Horsfield B, Skeie JE, et al. Petroleum retention in the mandal formation, central Graben, Norway. Mar Pet Geol. 2017;83:195214. https://doi.org/10.1016/j.marpetgeo.2017.03.005. 